\title{
Renal processing of glucose in well and sick neonates
}

Malcolm G Coulthard, Edmund N Hey

\begin{abstract}
Aims-To determine the extent of renal processing of glucose in sick and well neonates.

Methods-Glomerular filtration rate (GFR) and the renal processing of glucose, sodium, and water were measured using prolonged inulin infusion in 47 infants of 26-40 weeks of gestation, aged 1-13 days. Results-GFR rose by $15 \%$ after ventilatory support was withdrawn, and was unaffected by clinical instability. Fractional glucose excretion was low in the stable unventilated babies except at very high filtered loads, but rose in one unstable, unventilated baby. It was higher in ventilated babies, and remained high for at least six days after ventilation. For water and sodium, net differences between intake and urine excretion were not affected by ventilation, clinical stability, or glycosuria.

Conclusions-A combination of a low GFR and a high fluid intake, urine flow, and urine concentrating capacity, makes neonates very unlikely to develop an osmotic diuresis due to glycosuria while they have a blood glucose below $12 \mathrm{mmol} / 1$, despite assertions to the contrary. (Arch Dis Child Fetal Neonatal Ed 1999;81:F92-F98)
\end{abstract}

Keywords: glomerular filtration rate; renal glucose; renal sodium; osmotic diuresis

Much of our understanding of the pathophysiology of glucose processing by the neonatal kidney is extrapolated from subgroups of infants, older subjects, or from animal studies; few studies have included both stable and ill babies. The accepted advice is to reduce the glucose intake of preterm infants with glycosuria because they are felt to be at risk of osmotic diuresis, but we can find no published evidence in support of this assertion. Indeed, it could be argued that, in the absence of marked hyperglycaemia, the physiology of neonatal kidneys would make a glucose induced osmotic diuresis

Table 1 Patient details

\begin{tabular}{|c|c|c|c|c|c|c|c|c|c|}
\hline \multirow[b]{2}{*}{ Patient category } & \multirow[b]{2}{*}{$N=$} & \multicolumn{2}{|c|}{ Gestation (weeks) } & \multicolumn{2}{|c|}{ Birthweight (kg) } & \multicolumn{2}{|c|}{ Postnatal age (days) } & \multirow[b]{2}{*}{ Unstable } & \multirow[b]{2}{*}{ Survival } \\
\hline & & Mean & (Range) & Mean & (Range) & Mean & (Range) & & \\
\hline Never ventilated & 23 & $\begin{array}{l}33.2 \\
\star\end{array}$ & $(26-40)$ & 1.74 & $(0.68-3.71)$ & 3.3 & $(1.1-13.5)$ & 0 & 23 \\
\hline Currently ventilated & 22 & 29.7 & $(26-37)$ & 1.44 & $(0.64-4.65)$ & $\begin{array}{l}4.2 \\
\star\end{array}$ & $(1.0-9.2)$ & 10 & 13 \\
\hline Previously ventilated & 12 & 30.1 & $(27-37)$ & 1.40 & $(0.90-3.10)$ & 7.1 & $(2.0-13.9)$ & 4 & 9 \\
\hline Twin-pair & 2 & 32 & & $1.42 \&$ & .43 & 1.9 to & & 1 & both \\
\hline
\end{tabular}

${ }^{\star}$ Means differ significantly, $\mathrm{p}<0.05$. unlikely, given their relatively low glomerular filtration rate $(\mathrm{GFR})^{1}$ which limits the filtered load of glucose, their high fractional excretion of water, ${ }^{2}$ and their capacity to concentrate urine.

We measured renal function by continuous inulin infusion ${ }^{3}$ in stable and unstable neonates, to assess the effects of ventilation and clinical instability on renal glucose processing, and the impact of that on water and electrolyte balance.

\section{Methods}

Forty seven infants who required intravenous fluids for clinical reasons had their renal function measured by prolonged inulin infusion. This was part of a study which had been approved by Newcastle Health Authority and the University Joint Ethics Committee. Informed parental consent was obtained.

Table 1 shows the clinical details. Some babies received all their fluids intravenously, but most also had milk. The sodium concentrations of their fluids were adjusted to provide 3 $\mathrm{mmol} / \mathrm{kg}$ daily (range 2.5-3.4). Diuretics were not prescribed. Humidified incubators were used to minimise insensible water loss. Babies were defined as being unstable at the time of sampling if, during the preceding 24 hours, they had had a blood $\mathrm{pH}<7.2$, or transcutaneous $\mathrm{pO}_{2}<6 \mathrm{kPa}$, or had sustained an adverse event such as a pneumothorax or congestive cardiac failure, or had been judged by the nursing or medical staff to be clinically unwell. They were defined as being stable if they had none of these.

As the study was designed to investigate how renal function changes as babies' clinical conditions alter, inulin was infused continuously for as much of the first two weeks of life as intravenous treatment could be maintained, and samples were taken on mornings when it had been infused without major interruption for at least 24 hours. Because babies had intravenous lines for different periods of time, the number of samples obtained varied widely. To prevent any individual baby from biasing the

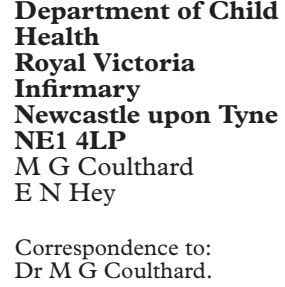

Accepted 7 April 1999 

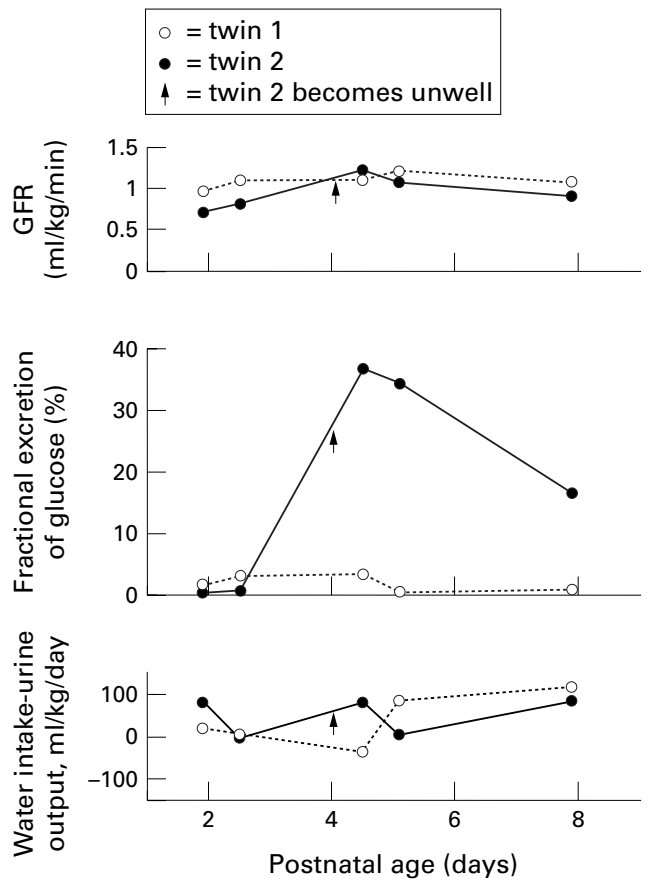

Figure 1 Sequential GFR, fractional excretion of glucose, and net differences between water intake and urine output measurements in a twin pair.

results, just one sample was selected at random for analysis from each of the 23 babies who were never ventilated, and one from each of the 22 who were studied while being ventilated. Twelve of the ventilated babies were studied further after being weaned off the ventilator; a second sample was therefore selected at random from these infants for analysis. Serial data are presented graphically from those 12 babies who were studied both during and after ventilation, and from the 23 babies who were never ventilated. Serial data are also presented on a twin pair whose results are not included in the statistical analysis.

The 23 babies who did not require ventilation were stable throughout. One received caffeine for mild apnoea, and eight received peni-

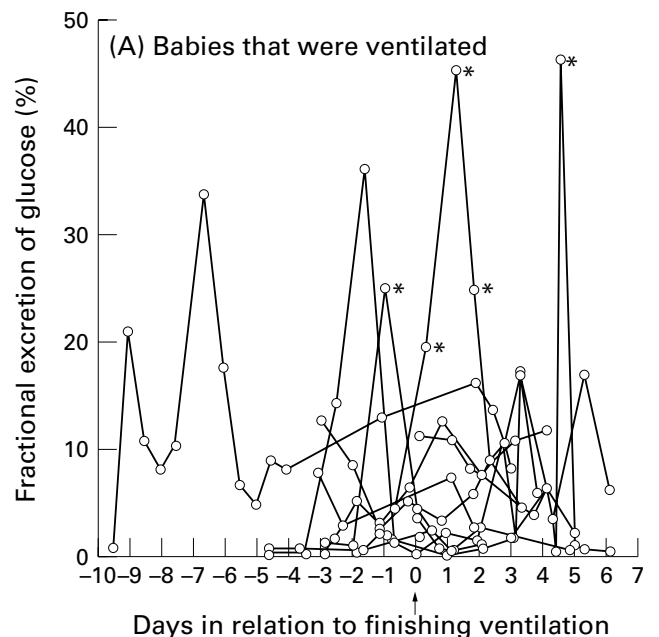

cillin and gentamycin for two days because of prolonged rupture of membranes. Of the 22 babies who required intermittent positive pressure ventilation, nearly half were unstable at the time of sampling, as were one third of those sampled after ventilation had been withdrawn. Eight received caffeine, 14 received penicillin and gentamycin, and three received tolazoline, but none had indomethacin. Of the twin pair studied sequentially from 1.9 to 7.9 days, twin 1 remained clinically stable throughout, but twin 2 developed radiologically confirmed necrotising enterocolitis and became unstable at 4 days of age. He responded to treatment and did not require ventilation, and was therefore the only non-ventilated, unstable infant studied.

GFR and urine flow rate were estimated from the infusate, plasma, and urine inulin concentrations after inulin had been infused intravenously at $15 \mathrm{mg} / \mathrm{kg}$ per hour for at least 24 hours. $^{3}$ An extra $150 \mu$ l of blood was taken by heel prick when babies were sampled for clinical purposes, and urine was collected immediately after the baby had voided on to a plastic sheet. GFR was calculated as the inulin infusion rate divided by the plasma inulin concentration, and the urine flow rate as the infusion rate divided by the urine inulin concentration; both were expressed per kilogram, ${ }^{4}$ using birthweight, in view of their age. Filtered loads of substances were calculated from their plasma concentrations and GFR, excretion rates from their urine concentrations and urine flow rates, and their fractional excretions - as their excretion rates divided by their filtered loads-were expressed as a percentage. Free water clearance was calculated as the product of the urine flow rate, and the difference between the plasma and urine osmolalities divided by the plasma osmolality. The net daily differences between the intake and urine output of sodium and water ("balances," but not accounting for insensible and stool losses) were estimated from the recorded daily sodium and fluid intakes, and the sodium excretion and

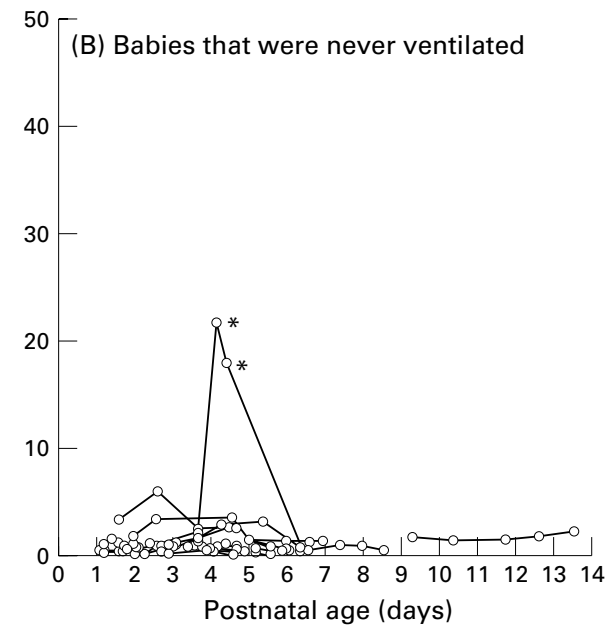

* = times when babies were hyperglycaemic (blood glucose above $12 \mathrm{mmol} / \mathrm{l}$ ).

Figure 2 Serial fractional excretion of glucose values for individual babies: (A) plotted against time ventilated in the 12 babies studied during and after ventilation; and (B) plotted against postnatal age in the 23 babies who were never ventilated. 
Table 2 Effects of ventilation status and clinical stability on GFR, and on renal processing of glucose, water, and sodium

\begin{tabular}{|c|c|c|c|c|}
\hline & \multicolumn{4}{|c|}{ Ventilation status } \\
\hline & \multicolumn{2}{|c|}{ Babies never vs currently ventilated } & \multicolumn{2}{|c|}{ Babies currently vs previously ventilated } \\
\hline & $\begin{array}{l}\text { Never } \\
(n=23)\end{array}$ & $\begin{array}{l}\text { Currently } \\
(n=22)\end{array}$ & $\begin{array}{l}\text { Currently } \\
\text { (pairs, } n=12 \text { ) }\end{array}$ & Previously \\
\hline $\mathrm{GFR}, \mathrm{ml} / \mathrm{kg} / \mathrm{min}$ & $0.97(0.06) \dagger$ & $0.79(0.04)$ & $0.79(0.06) \dagger$ & $0.91(0.06)$ \\
\hline \multicolumn{5}{|l|}{ Glucose } \\
\hline fractional excretion, $\%$ & $2.1(0.8) \dagger$ & $7.6(2.0)$ & $10.1(2.9)$ & $9.3(3.7)$ \\
\hline \multicolumn{5}{|l|}{ Water processing } \\
\hline (i) intake, $\mathrm{ml} / \mathrm{kg} /$ day & $144(9.4)$ & $124(7.7)$ & $133(12.7)^{\star}$ & $171(14.3)$ \\
\hline (ii) "net difference", $\mathrm{ml} / \mathrm{kg} /$ day $§$ & $18.8(10.3)$ & $34.6(12.3)$ & $29.7(16.5)$ & $30.1(19.6)$ \\
\hline (iii) fractional excretion, $\%$ & $9.8(0.9)$ & $8.1(0.9)$ & $9.0(1.0)$ & $10.9(1.3)$ \\
\hline (iv) free clearance, $\mathrm{ml} / \mathrm{kg} / \mathrm{day}$ & $81(11.0) \ddagger$ & $26(8.3)$ & $31(14.1)$ & $79(8.7)$ \\
\hline \multicolumn{5}{|l|}{ Sodium processing } \\
\hline (i) "net difference", $\mathrm{mmol} / \mathrm{kg} /$ day $§$ & $-0.17(0.38)$ & $-1.27(0.63)$ & $-1.69(0.84)$ & $-2.06(0.69)$ \\
\hline (ii) fractional excretion, $\%$ & $1.6(0.2)$ & $2.5(0.5)$ & $2.9(0.9)$ & $2.7(0.3)$ \\
\hline
\end{tabular}

All values are shown as mean (SE).

$P$ values: ${ }^{\star}<0.05, \dagger<0.01, \neq<0.001$.

$\S$ Note: "net differences" refer to the differences between the daily estimated intakes and excretion rates of sodium or water,

measured at the time of daily sampling. Unlike a true balance, it does not take insensible or stool losses into account.

urine flow rates, measured at the time of sampling and projected over 24 hours. $^{2}$ Glucose was measured using a glucose oxidaseperoxidase method, sodium and potassium by flame photometry, and osmolality by depression of freezing point.

To consider the effects of ventilation, results from the 23 babies who were never ventilated were compared with the 22 currently ventilated babies, using the $t$ test for normally distributed variables, and the Mann-Whitney $U$ test for non-normal data. Results from the 12 babies investigated both during and after ventilation were compared using the paired $t$ test for normally distributed variables and the Wilcoxon matched pairs test for skewed data. The effect of clinical instability was studied in three ways. First, all 35 stable babies in the never and currently ventilated groups were compared with the 10 unstable ventilated babies, and second, the 12 stable and 10 unstable currently ventilated babies were compared, using either the $t$ test or the Mann-Whitney U test. Finally, sequential multiple regression analysis was performed on the never and currently ventilated groups combined, to assess the effects of individual factors once the influence of other variables had been taken into account. Spearman rank and sequential multiple regression analysis were used to examine the relation between urinary sodium and glucose excretion. Statistical significance was taken as $\mathrm{p}<0.05$. Data on the twin pair are presented graphically (fig 1), but not analysed further. Individual data points were also plotted for the fractional excretion of glucose against time for the non-ventilated babies, and those studied during and after ventilation (fig 2).

\section{Results}

The babies who were never ventilated were, on average, 3.5 weeks more mature than those who were, but birthweights and postnatal ages were not significantly different (table 1 ). Babies studied during and after ventilation had their second sample taken an average of 2.9 (1.0 to 9.1) days after the first, and 2.2 (0.5 to 4.8) days after ventilation had been discontinued. Table 2 gives details of GFR, and of the renal processing of glucose, water, and sodium in relation to ventilation status and clinical stability.

GLOMERULAR FILTRATION RATE

All the GFR values fell within the ranges reported for stable babies of similar gestation. ${ }^{1}$ They were lower in the currently ventilated babies than in those that had never been ventilated, but this difference is only slightly larger than would be expected because of differences in gestational age. ${ }^{1}$ The 12 babies studied both during and then after ventilation had been withdrawn, showed a significant rise in GFR of $15 \%(\mathrm{p}<0.01)$. This rise is larger than would be expected from their slightly greater postnatal age when studied off ventilation (predicted increase $=0.79$ to $0.81 \mathrm{ml} / \mathrm{kg} /$ minute $\left.^{1}\right)$, but the difference between this predicted GFR and the measured value just failed to reach significance $(p=0.06)$. The slightly lower GFR in unstable babies, compared either with a mixed group of stable babies, or with ventilated stable babies, was not significant. Multiple regression analysis of the combined groups of never and currently ventilated babies confirmed that, after ventilation status had been accounted for, GFR was not affected by clinical stability $(p=0.62)$. In the twins studied there was no obvious change in GFR after twin 2 became unstable (fig 1).

RENAL HANDLING OF GLUCOSE

Carbohydrate intake averaged $7.9 \mathrm{mg} / \mathrm{kg} /$ minute (range 4.2 to 15.9 ), and plasma glucose concentrations averaged $5.7 \mathrm{mmol} / 1$ (range 1.0 to 20.0, with two values under 2.2 , and one over 12). Glucose reabsorption was relatively complete at low filtered loads, but spillage increased gradually at higher loads; the classic pattern, ${ }^{5}$ but with greater splay. Figure 3 shows the percentage of the filtered glucose that is spilt into the urine (fractional excretion of glucose), against the $\log _{10}$ of the filtered load, and demonstrates that the spill is greater across the whole range of filtered loads in babies who are being, or have been, ventilated. Table 2 confirms a threefold increase in the fractional excretion of glucose in ventilated compared with non-ventilated babies, which persists after 
Table 2 cont'd

\begin{tabular}{lllll}
\multicolumn{2}{l}{ Clinical stability } & & \\
\cline { 1 - 2 } $\begin{array}{l}\text { Including ventilated and unventilated babies } \\
(n=35)\end{array}$ & $\begin{array}{l}\text { Unstable } \\
(n=10)\end{array}$ & & $\begin{array}{l}\text { Stable } \\
(n=12)\end{array}$ & $\begin{array}{l}\text { Unstable } \\
(n=10)\end{array}$ \\
\hline $0.91(0.04)$ & $0.76(0.07)$ & $0.81(0.06)$ & $0.76(0.07)$ \\
$5.2(1.5)$ & $3.6(1.3)$ & $10.9(3.2)$ & $3.6(1.3)$ \\
$141(7.6)^{\star}$ & $111(4.1)$ & $135(13.1)^{\star}$ & $111(4.1)$ \\
$22.6(6.9)$ & $40.8(12.8)$ & $29.5(20.0)$ & $40.8(12.8)$ \\
$9.6(0.7)$ & $6.6(1.1)$ & $9.3(1.3)$ & $6.6(1.1)$ \\
$69(9.3) \dagger$ & $17(7.7)$ & $39(15.1)$ & $17(7.7)$ \\
$-0.74(0.36)$ & $-0.64(1.13)$ & & $-1.79(0.65)$ & $-0.64(1.13)$ \\
$2.0(0.2)$ & $2.2(0.9)$ & $2.8(0.4)$ & $2.2(0.9)$ \\
\hline
\end{tabular}

ventilation. Figure 2 is a plot of the serial values of fractional excretion of glucose for individual babies against time. The only non-ventilated baby to have very high values did so while very hyperglycaemic (fig 2B), whereas many ventilated babies have high values while euglycaemic, and continue to do so for up to six days after coming off ventilation (fig 2A). Neither clinical stability, nor gestational or postnatal age, has a measurable effect on the fractional excretion of glucose.

The twins had fractional excretions of glucose under $4 \%$ until twin 2 developed necrotising enterocolitis, when his rose to over $35 \%$ within 12 hours, and then fell slowly (fig $1)$. The slight rise in his blood glucose and fil-

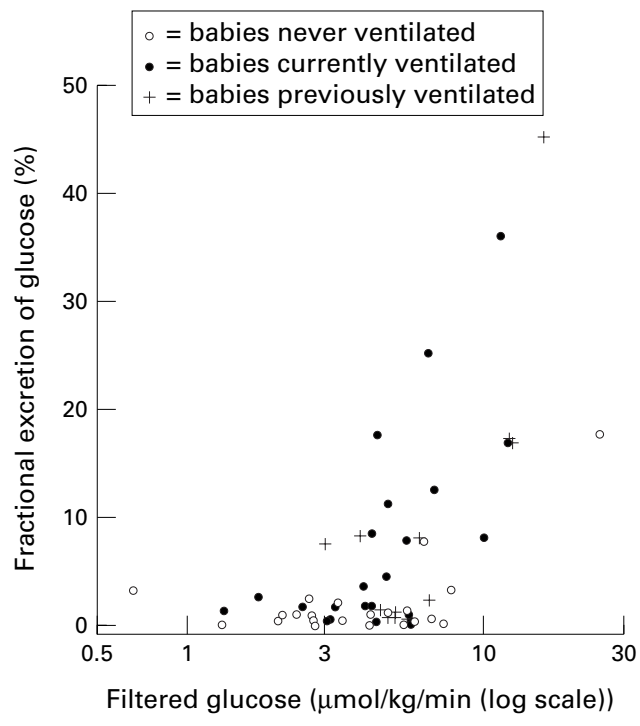

Figure 3 Plot of fractional excretion of glucose against filtered load (log scale).

Table 3 Multiple regression of free water clearance and net difference between daily water intake and urine output

\begin{tabular}{llllll}
\hline & \multicolumn{2}{l}{ Free water clearance } & & \multicolumn{2}{l}{ Water intake - urine output } \\
\cline { 2 - 3 } & $(r$ value $)$ & $(p$ value $)$ & & $(r$ value $)$ & $(p$ value $)$ \\
\hline Water intake & 0.51 & 0.003 & & 0.24 & 0.11 \\
Ventilation status & -0.35 & 0.02 & & 0.15 & 0.23 \\
Glucose excretion & -0.36 & 0.03 & & 0.60 & 0.0001 \\
Clinical stability & -0.18 & 0.32 & & 0.21 & 0.08 \\
Sodium excretion & 0.04 & 0.82 & & -0.57 & 0.0001 \\
\hline
\end{tabular}

tered load after he became unstable do not account for his massive increase in glucose spillage.

WATER AND SODIUM PROCESSING

The unstable babies were, as a matter of unit policy, given a lower water intake than either of the stable groups, and the currently ventilated babies were given less water than the previously ventilated ones. Neither ventilatory status, nor clinical stability, affected the net daily differences between intake and output, or the fractional excretion rates of sodium or water. The slightly negative sodium balance seen in most of the infants was close to that reported by others for babies of similar gestational and postnatal ages, and probably reflects the loss of extracellular fluid during the first few days of life. ${ }^{6}$ The free water clearance was more than $50 \mathrm{ml} / \mathrm{kg} /$ day lower in the ventilated babies than those never ventilated; there was a similar difference between babies during and after ventilation, but that did not reach significance. Among ventilated infants, clinical stability had no effect on the free water clearance; a difference is seen only if unstable (ventilated) babies are compared with the stable group in which ventilated and non-ventilated infants are combined. Sequential multiple regression analysis of factors affecting free water clearance (table 3) confirms the expected positive relation with water intake, and that it is affected by the ventilation status, but not the clinical stability once ventilation has been taken into account. It also indicates a negative relation with glucose excretion, and none with sodium excretion. Multiple regression also confirms that the net difference between the intake of water and output of urine is not significantly affected by water intake, ventilation status, or clinical stability, and that it is negatively correlated with sodium excretion $\left(\mathrm{r}^{2}=0.32\right)$, but positively correlated with glucose excretion (table 3). The associated natriuresis and diuresis probably reflects physiological contraction of extracellular fluid.

Sodium excretion was positively associated with urinary glucose loss (Spearman rank), whether expressed as the fractional excretion of glucose $(p<0.02)$, or its excretion rate $(\mathrm{p}<0.05)$. However, sequential multiple regression showed a correlation only between the sodium excretion and the fractional excretion of glucose $(p<0.001)$, and none with the glucose excretion rate $(p=0.7)$, once its fractional excretion had been taken into account.

The twin pair received identical sodium and water intakes. Free water clearance in twin 2 fell as the fractional excretion of glucose rose at 4.5 days, but the net differences between their intakes and urinary losses of sodium and water remained similar throughout (fig 1).

URINE OSMOLALITY

The urine osmolality ranged from 39 to $434 \mathrm{mosmol} / \mathrm{kg}$, and was less than plasma osmolality in all but six cases. The contributions of glucose, sodium, potassium and urea $(n=40)$ to the urinary osmolality are shown in 


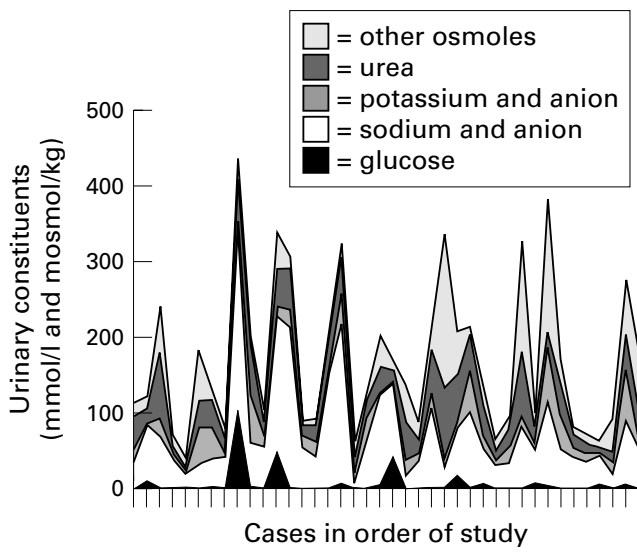

Figure 4 Urinary constituents in the 40 cases for whom data were available, plotted in order of cases studied.

fig 4 , in which sodium and potassium concentrations are doubled as they are assumed to be accompanied by monovalent anions. Sodium and its anion made up the largest osmolar load in most urines, glucose seldom contributing more than $10 \%$ of the total. Several urines showed at least a trace or more of glycosuria on stick tests; two showed about $1 \%(56 \mathrm{mmol} / \mathrm{l})$, and one about $2 \%$.

\section{Discussion}

Our results show slightly lower values of GFR in babies requiring ventilatory support, which recovers once off ventilation. Previous authors have either reported no change $\mathrm{e}^{7-11}$ or a slight reduction ${ }^{12-15}$ of GFR in babies requiring ventilation for respiratory distress, but several have estimated the GFR from creatinine concentrations $^{78^{13-15}}$ which are known to be affected by very variable plasma non-creatinine chromogen concentrations in neonates. ${ }^{16}$

The reduction in GFR during ventilation is likely to be due to the instability of physiological variables, such as the renal blood flow. This has been shown to be lower in two groups of unwell preterm babies; in infants ventilated for severe respiratory distress compared with ventilated controls, ${ }^{17}$ and in unventilated neonates with a patent arterial duct. ${ }^{18}$ Our study cannot clarify which mechanisms were responsible for the reduced GFR because we did not make haemodynamic assessments, such as blood flow measurements, continuous blood pressure, or central-peripheral temperature gradient monitoring, or sampling for vasopressin concentrations. ${ }^{19}$

As far as we are aware, this is the first systematic study of renal glucose processing to include well, preterm infants. Even the most immature of the non-ventilated, clinically stable babies reabsorbed a high proportion of their filtered glucose. The increased fractional excretion of glucose in babies who were being ventilated (which persisted after ventilation had been discontinued) was a striking and unexpected finding, although the range of values we found was very similar to those reported in sick, very low birthweight infants, $95 \%$ of whom had also required ventilatory support. $^{20}$
An increase in the fractional excretion of glucose occurring at the same filtered load indicates a reduction in the tubular transport maximum for glucose reabsorption. The increase in fractional excretion of glucose did not begin at a sharply defined level of filtered load, but, rather, was a splayed curve suggesting individual nephron heterogeneity; puppies show a similarly splayed curve compared with adult dogs. ${ }^{21}$ The mechanism for the increase in fractional excretion of glucose is not evident from this study, but it is unlikely to be a direct result of intermittent positive pressure ventilation as such, both because it persisted for several days after ventilation was discontinued, and because it was an obvious feature in the non-ventilated twin, occurring promptly after a major stress. Clearly, the increase in fractional excretion of glucose among the ventilated and postventilated babies could occur as a result of an aspect of stress; the lack of association with clinical instability in our study may reflect its relatively insensitive assessment. Stonestreet showed that spontaneously breathing newborn lambs had increased natriuresis, glycosuria, and urine flow immediately after recovering from an acute asphyxial stress that was associated with a brisk rise in adrenalin and noradrenalin concentrations, but no alteration in renin activity. ${ }^{22}$ Providing ventilated babies routinely with opiate sedation substantially reduces their plasma adrenaline concentrations, ${ }^{23}$ but it is not known whether this influences their renal glucose processing. In future studies measurement of these stress hormones and other mediators of renal functional regulation might help to elucidate the mechanisms of neonatal renal glucose processing in humans.

It is widely believed that any baby with glycosuria is at risk of developing a clinically important osmotic diuresis, an assumption presumably extrapolated from the fact that children and adults with diabetic ketoacidosis may become dehydrated. As a result, the usual recommendation is to reduce glucose intakes in neonates with glycosuria.

Osmotic diuresis occurs when more solutes are excreted into the urine than can be dissolved in the volume of water that the baby would otherwise pass. This may happen when the spill of solutes is very high, when the urine volume needs to be especially small, when the maximum urine concentrating capacity is low, or any combination of these. The excretion of a solute load which exceeds the kidney's capacity to process it will result in an excessive loss of water, and may also lead to the retention of solutes-for example, of sodium, producing hypernatraemia. Thus to document a glucose induced diuresis, there needs to be a urinary spill of glucose sufficient to induce an extra loss of water, or to cause hypernatraemia, and not sufficient simply to report the presence of test strip positive glycosuria in an ill, dehydrated baby. Using these criteria, we have been unable to find a single reliably documented description of a neonate with dehydration secondary to a glycosuria induced diuresis. Stonestreet presented high values of fractional sodium excretion as evidence of a diuresis, ${ }^{24}$ but cited 
values subsequently shown to be normal for stable neonates. ${ }^{6}$ She also assumes that the increased urine flow in asphyxiated lambs was due to a glucose driven osmotic diuresis, although her data do not support this. ${ }^{22}$ During the post-asphyxial peak in urine flow rate, the urine osmolality (382 mosmol/ $\mathrm{kg}$ ) was at its lowest level, and well within the regulatory range.

Our data allow us to speculate on whether glycosuria is likely to cause osmotic diuresis in a normoglycaemic neonate. A $1 \mathrm{~kg}$ baby with a blood glucose of $12 \mathrm{mmol} / \mathrm{l}$, and a GFR as high as $1.4 \mathrm{ml} / \mathrm{min}$, would have a daily filtered glucose load of $24 \mathrm{mmol}$ (a relatively low figure, because the neonatal GFR is relatively low ${ }^{1}$ ). If the fractional excretion of glucose was $50 \%$ (the highest we report), this would deliver an extra 12 mosmol to the urine per day. The effect of this on the urinary osmolality will depend on the urine flow rate. Neonates normally have a high fractional excretion of water, ${ }^{2}$ and produce large volumes of urine. Assuming a relatively low daily urine flow of only $75 \mathrm{ml}$, a glucose load of $12 \mathrm{mmol}$ would register $>2 \%$ glycosuria, but would add just $160 \mathrm{mosmol} / \mathrm{kg}$ to the urine osmolality (note: $1 \%$ glycosuria $=56 \mathrm{mmol} / 1$ glucose , which raises the urinary osmolality by $56 \mathrm{mosmol} /$ $\mathrm{kg}$ ). Unless the resultant urine osmolality exceeded the maximum tubular concentrating capacity, this would not cause an osmotic diuresis because the kidneys can control the excretion of water and solutes independently. As neonatal urine is usually dilute, and the maximum concentrating capacity is about $600 \mathrm{mosmol} / \mathrm{kg}$, a typical preterm baby would have the capacity easily to cope with this amount of extra solute excretion. The maximum renal concentrating capacity is not fixed, but depends on urine flow rate. ${ }^{25}$ For example, it may be significantly reduced by the diuresis from water loading. However, with water loading, the baby's urine osmolality will be much lower, and an even greater capacity for extra solute excretion will exist. The worked example (which assumes worst case conditions) therefore suggests that there is no likelihood of a glucose induced osmotic diuresis occurring in a normoglycaemic baby. It is not surprising that no baby has ever been shown to have clear evidence of such a diuresis.

By contrast, it is clear that a hyperglycaemic infant could increase its urinary glucose osmotic load dramatically, sufficient to cause a diuresis. In the worked example, if the maximum tubular capacity remained the same, but the blood glucose concentration was doubled to $24 \mathrm{mmol} / \mathrm{l}$, the glucose spill would treble, and the potential urine osmolality needed to carry it would increase by nearly 500 mosmol $/ \mathrm{kg}$. It is highly unlikely that the kidney could achieve this. The presence of glycosuria should be an indication to measure the blood glucose, rather than to reduce automatically the carbohydrate intake. In most cases the baby will be normoglycaemic, the risk of diuresis will be non-existent, and reducing the carbohydrate intake would not eradicate the glycosuria until the baby had been rendered hypoglycaemic.
Hyperglycaemic babies could have their glucose intake appropriately reduced, or be offered insulin treatment.

The arguments associating urinary glucose excretion with risk of osmotic diuresis apply equally to all the solutes that make up the renal osmolar load. In our study sodium was often the largest and most variable contributor to the urine osmolality, despite a similar intake in all babies, and variations in the sodium excretion affected the estimated water balance, accounting for $31 \%$ of its variability. An uncontrolled natriuresis has been described in neonates who are severely stressed, and have the appearance of acute septicaemia. ${ }^{26}$ Using continuous inulin infusion, we have observed four similar cases occurring after major stress where a sudden brisk natriuresis lasting up to two days led to hyponatraemia, but did not alter the urine flow rate. In this study, we have shown an association between babies having a high fractional excretion of glucose and increased urinary sodium loss, and shown that this is not driven directly by the quantity of glycosuria. It might be that milder levels of stress affect the tubular processing of glucose, but not sodium processing, and that relatively more severe levels of stress may induce a transient uncontrolled natriuresis. A natriuresis is especially likely to cause an osmotic diuresis because the filtered load of sodium is so large, parallelling its high plasma concentration. Babies with such a sodium induced diuresis are likely to be ventilated, and thus also to have glycosuria, so glucose may falsely be deemed to be the culprit. In clinical practice daily excretion rates of sodium and potassium $(\mathrm{mmol} / \mathrm{kg})$ may be estimated conveniently from a spot urine sample as 70 times the ratio of their concentrations (mmol/ $1)$, to creatinine $(\mu \mathrm{mol} / \mathrm{l}){ }^{16}$

Because an increase in the excretion of any one solute could summate with others to exceed the concentrating capacity of the kidney, it makes sense to monitor for the risk of an osmotic diuresis with regular urine osmolality measurements - a baby with a value near $600 \mathrm{mosmol} / \mathrm{kg}$ is likely to benefit from extra water, regardless of which solutes make up the osmoles. We recommend measuring the urine osmolality and checking for glycosuria daily on all very small and unwell babies. Their water intakes should be adjusted to keep the osmolality in the range 80 to $400 \mathrm{mosmol} / \mathrm{kg}$. ${ }^{2}$ If they have $1 \%$ or more of glycosuria, their blood glucose should be monitored, and adjusted if it is unacceptably high.

We thank the nursing staff of the Princess Mary Maternity Hospital Special Care Nursery, Newcastle upon Tyne, for their help and support.

This Work was funded by MRC Project Grant 9979279

1 Coulthard MG. Maturation of glomerular filtration in preterm and mature babies. Ear Hum Dev 1985;11:281-92. 2 Coulthard MG, Hey EN. The effect of varying water intake on renal function in healthy preterm babies. Arch Dis Child 1985;60:614-20.

3 Coulthard MG. A comparison of methods of measuring renal function in preterm babies using inulin. $\mathcal{F}$ Pediatr $1983 ; 102 \cdot 923-30$

4 Coulthard MG, Hey EN. Weight as the best standard for glomerular filtration in the newborn. Arch Dis Child glomerular filtr.

5 Smith HW. Principles of renal physiology. New York: Oxford University Press, 1956. 
6 Al-Dahhan J, Haycock GB, Chantler C, Stimler L. Sodium homeostasis in term and preterm neonates. Part I. Renal aspects. Arch Dis Child 1983;58:335-42.

7 Siegel SR, Fisher DA, Oh W. Renal function and serum aldosterone levels in infants with respiratory distress syndrome. F Pediatr 1973;83:854-8.

8 Engelke SC, Shah BL, Vasan U, Raye JR. Sodium balance in very low birth weight infants. F Pediatr 1978;93:837-41.

9 van der Heijden AJ, Grose WF, Ambagtsheer JJ, Provoos $\mathrm{AP}$, Wolff ED, Sauer PJ. Glomerular filtration rate in the preterm infant: the relation to gestational and postnatal age. Eur f Pediatr 1988;148:24-8.

10 Vanpee M, Herin P, Zetterstrom R, Aperia A. Postnatal development of renal function in very low birthweight infants. Acta Paediatr Scand 1988;77:191-7.

11 Wilkins BH. Renal function in sick very low birthweight infants: 1. Glomerular filtration rate. Arch Dis Child 1992;67:1140-5.

12 Guignard JP, Torrado A, Mazouri SM, Gautier E. Renal function in respiratory distress syndrome. $\mathcal{f}$ Pediatr function in respi

13 Tulassay T, Ritvay J, Bors ZS, Buky B. Alterations in creatinine clearance during respiratory distress syndrome. Biol nine clearance during respir

14 Leslie GI, Philips JB-III, Work J, Ram S, Cassady G. The effect of assisted ventilation on creatinine clearance and hormonal control of electrolyte balance in very low birthweight infants. Pediatr Res 1986;20:447-52.

15 Vanpee M, Ergander U, Herin P, Aperia A. Renal function in sick, very low-birth-weight infants. Acta Paediatr 1993;82:714-8.

16 Coulthard MG, Hey EN, Ruddock V. Creatinine and urea clearances compared to inulin clearance in preterm and mature babies. Ear Hum Dev 1985;11:11-19.
17 van de Bor M, van Bel F, Guit GL, Schipper J. Renal blood flow velocity in preterm infants with severe respiratory distress syndrome. F Pediatr 1990;117:785-8.

18 Visser MOJM, Leighton JO, van de Bor M, Walther FJ. Renal blood flow in neonates: quantification with color flow and pulsed doppler US. Radiol 1992;183:441-4.

19 Lambert HJ, Baylis PH, Coulthard MG. Central-peripheral temperature difference, blood pressure, and arginine vasopressin in preterm neonates undergoing volume expanpressin in preterm neonates underg
sion. Arch Dis Child 1998;78:F43-5.

20 Wilkins BH. Renal function in sick very low birthweight infants: 4. Glucose excretion. Arch Dis Child 1992;67: 1162-5.

21 Arant BS, Edelmann CM, Nash MA. The renal reabsorption of glucose in the developing canine kidney; a study of glomerular tubular balance. Pediatr Res 1974;8:638-46.

22 Stonestreet BS, Laptook AR, Siegel SR, Oh W. The renal response to acute asphyxia in spontaneously breathing newborn lambs. Ear Hum Dev 1984;9:347-61.

23 Wood CM, Rushforth JA, Hartley R, Dean H, Wild J, Levene MI. Randomised double blind trial of morphine versus diamorphine for sedation of preterm neonates. Arch Dis Child 1998;79:F34-9.

24 Stonestreet BS, Rubin L, Pollack A, Cowett RM, Oh W. Renal functions of low birthweight infants with hyperglycaemia and glucosuria produced by glucose infusions. caemia and glucosuria p
Pediatrics 1980;66:561-7.

25 Gennari FJ, Kassirer JP. Osmotic diuresis. N Engl f Med 1974;291:714-20.

26 Wilkins $\mathrm{BH}$. Renal function in sick very low birthweight infants: 3. Sodium, potassium and water excretion. Arch Dis Child 1992;67:1154-61. 